\title{
Conferência
}

\section{Dignidade da pessoa humana: ortopraxia cristã ou utopia?}

\author{
Dignity of human person: \\ chistian ortopraxy or utopia?
}

Felipe de Moraes Negro ${ }^{1}$
D $0000-0002-9863-1163$

\section{Resumo}

Este artigo busca compreender a dinâmica da dignidade da pessoa humana expandindo o horizonte da reflexão feita pelo Monsenhor Bruno-Marie Duffé em sua conferência "O que quer dizer considerar a dignidade da pessoa humana?", numa articulação com a encíclica "Populorum Progressio - sobre o desenvolvimento dos povos", do Papa São Paulo VI. Para atingir esse objetivo, apresentou-se e articulou-se à reflexão o curta-metragem brasileiro "Ilha das Flores", que demonstra a precariedade do modo capitalista de organizar a sociedade quando se trata de considerar humanas todas as pessoas, inclusive as que são descartadas pela ordem vigente. E, para demonstrar que o desenvolvimento humano e integral deve se dar na promoção do homem todo e de todos os homens, a categoria Reino de Deus, enquanto utopia e ortopraxia, foi colocada em destaque a partir das considerações do teólogo Leonardo Boff em sua obra "Jesus Cristo Libertador".

Palavras-chaves: Desenvolvimento integral. Dignidade da pessoa humana. Ortopraxia. Reino de Deus. Utopia.

\begin{abstract}
This article seeks to understand the dynamics of the dignity of the human person, expanding the hori-zon of the reflection made by Monsignor Bruno-Marie Duffé in his Conference "What does it mean to consider the dignity of the human person?", in conjunction with the Encyclical "Populorum Progression - on the development of peoples", by Pope São Paulo VI. To achieve this goal, the Brazilian short film "Iha das Flores" was presented and articulated for reflection, which demonstrates the precariousness of the capitalist way of organizing society, when it comes to considering all human beings, including those that are discarded by the current order. And, to demonstrate that human and integral develop-ment must take place in the promotion of the whole man and of all men, the Kingdom of God category, as utopia and orthopraxy, was highlighted based on the considerations of theologian Leonardo Boff, in his work "Jesus Christ the Liberator".
\end{abstract}

Keywords: Integral development. Dignity of the human person. Orthopraxy. God's kingdom. Utopia.

\section{Introdução}

Este artigo quer servir de expansão de um diálogo a partir da conferência "O que quer dizer considerar a dignidade da pessoa humana?", proferida pelo Monsenhor Bruno-Marie

\footnotetext{
1 Pontifícia Universidade Católica de Campinas, Centro de Ciências Humanas e Sociais Aplicadas, Programa de Pós-Graduação em Ciências da Religião. R. Prof. Dr. Euryclides de Jesus Zerbini, 1516, Parque Rural Fazenda Santa Cândida, 13087-571, Campinas, SP, Brasil. E-mail: padrefenegro12@gmail.com
} 
Duffé, secretário do Dicastério para o Desenvolvimento Humano Integral - Vaticano, na Pontifícia Universidade Católica de Campinas durante o seminário promovido pelo Núcleo de Fé e Cultura no dia 13 de maio de 2019 (DUFFÉ , 2019).

No primeiro tópico buscar-se-á apresentar a carta encíclica "Populorum Progressio", do Papa São Paulo VI, num diálogo com o curta-metragem brasileiro "Ilha das Flores", a fim de promover uma conversa acerca da urgência de um olhar atento sobre as realidades dos tempos atuais à luz do Evangelho.

Em seguida, demonstrar-se-á uma reflexão sobre o Reino de Deus como perspectiva da realização prática da utopia que emerge do coração humano, a partir das considerações do teólogo Leonardo Boff no livro "Jesus Cristo Libertador".

\section{Desenvolvimento é o novo nome da Paz}

A celebração da páscoa, que significa a ressurreição do Senhor, é o ponto alto da liturgia de toda Igreja, pois concentra o referencial majoritário da fé cristã e evidencia, através dos sinais sacramentais, o acontecimento fundante e fundamental da mesma Igreja. Um dos sinais mais expressivos da páscoa é o canto do Aleluia, que contém em si toda a expressão daquele evento do qual originam a Igreja e a fé cristã. Esse canto está presente em todas as celebrações da eucaristia ao longo do ano, com exceção das da quaresma. Isso significa que o ano todo é permeado do evento pascal de Cristo.

A páscoa de 1967 teve um tom diferenciado, pois o brado aleluiático que emergiu de dentro do túmulo do Crucificado-Ressuscitado carregou junto de si o grito lancinante dos marginalizados e empobrecidos de todo o mundo de então. O Papa São Paulo VI foi porta-voz de muitas pessoas que não têm voz nem vez; aqueles que não são considerados, nem vistos. A carta encíclica "Populorum Progressio - sobre o desenvolvimento dos povos" foi assinada e divulgada justamente nesse dia, como se fosse a encíclica da ressurreição ${ }^{2}$ de tantas pessoas humanas unidas à Ressurreição do Cristo Senhor.

Essa encíclica reflete a preocupação do Magistério Pontifício da Igreja acerca das questões sociais, evidenciadas na esteira das grandes encíclicas desde a Rerum Novarum, de Leão XIII, pois é tarefa da Igreja "[...] projetar nas questões sociais de seu tempo a luz do Evangelho" (PAULO VI, 1967, n. 2). Desse modo, faz-se necessário analisar diversos pontos importantes que compõem a carta encíclica, sobretudo em sua primeira parte, pois as preocupações nela evidenciadas constituem um grito histórico e, ao mesmo tempo, mudo, uma vez que as urgências sociais denunciadas continu-am a sobrepujar a humanidade inteira desta época atual.

Chama a atenção a evidência que o Papa enfatiza: "[...] a questão social deve ser vista como preocupação universal" (PAULO VI, 1967, n. 3), ou seja, todos os países precisam estar atentos ao que acontece nas margens das diversas sociedades. Esse fator constitui-se num drama que se fez voz na encíclica: "[...] os povos da fome dirigem-se hoje, de modo dramático, aos povos da opulência. A Igreja estremece perante este grito de angústia e convida a cada um a responder com amor ao apelo do seu irmão" (PAULO VI, 1967, n.3).

\footnotetext{
${ }^{2}$ Frei Carlos Josaphat, em entrevista a Patrícia Facin, da Revista Online Unisinos. Disponível em: http://www.ihuonline.unisinos. br/artigo/6832-populorum-progressio-a-enciclica-da-ressurreicao.
} 
Isto posto, a denúncia escrita e dirigida pelo cineasta Jorge Furtado em 1989 no curta-metragem "Ilha das Flores" (ILHA..., 1989) é trazida à reflexão. Primariamente acusado de ser um filme materialista por trazer a frase "Deus não existe" já nas cenas iniciais, foi reconhecido como o melhor filme brasileiro do ano de 1990 através do Prêmio Margarida de Prata, concedido pela Conferência Nacional dos Bispos do Brasil (CNBB), e definido como filme religioso pelas críticas cineastas.

Em linhas gerais, "Ilha das Flores" não é um filme de ficção, pois retrata a condição subumana de pessoas humanas que vivem, de fato, numa ilha de Porto Alegre, na qual são descartados os mais diversos tipos de lixos, resíduos e rejeitos, e que sobrevivem à mercê desses descartes diários. O filme evidencia que, à época em questão, na cidade de Porto Alegre eram descartadas mais de 500 mil toneladas de lixo diariamente.

A questão de fundo é uma denúncia ao modo capitalista de organizar a sociedade, que é formada por bilhões de seres humanos que se distinguem dos outros seres vivos por terem um telencéfalo altamente desenvolvido e o polegar opositor, com os quais o ser humano conseguiu realizar muitos melhoramentos no planeta - entre eles, o plantio de tomates. Contudo, as imagens do filme sugerem que a invenção da bomba atômica foi um "melhoramento no planeta", como uma denúncia velada.

A esta altura, é possível se questionar sobre o que o plantio de tomates, elencado como um melhoramento feito pelo ser humano no planeta, tem a ver com a problemática deste artigo. Pois bem. Em nome do desenvolvimento dos povos, o capitalismo sugere a produção excessiva de alimentos, como o tomate - o que é feito por grandes, médios e pequenos produtores rurais, que trocam esses alimentos por dinheiro. Consecutivamente são selecionados e colocados à venda em grandes mercados, depois em médios e pequenos, até chegar à casa de uma família simples, por exemplo. Nessa família há quem trabalha; quem usa a sua inteligência também para trocar seu tempo e trabalho por dinheiro, a fim de poder comprar, dentre outras coisas, alimentos como o tomate -, que, como sugere o filme, quando levados para casa são novamente selecionados e os de qualidade inferior são descartados. Numa escala maior, todo esse descarte é conduzido aos grandes lixões, lugares distantes dos centros urbanos, mas que são, por diversas vezes, habitados também por pessoas humanas, como no caso da llha das Flores, em Porto Alegre.

No caso do filme em questão, daquele lixo orgânico que foi descartado anteriormente selecionam-se alimentos que serão oferecidos aos porcos, e o que sobrou dessa última seleção servirá de alimento para pessoas que não têm qualquer tipo de renda financeira e que se submetem a pegar esses restos de alimentos que foram rejeitados pelos empregados dos donos dos porcos e que antes foram rejeitados pelas famílias que gastaram seu dinheiro, fruto do trabalho e de sua inteligência, para selecionar os melhores tomates que servirão de molho para a carne de porco, como sugere o roteiro do filme.

Desse modo, ao trazer à reflexão um pouco da problemática denunciada pelo filme em questão, busca-se evidenciar que o ser humano que não possui dono ou dinheiro é entendido como resto e que, por uma misericórdia velada, também pode se alimentar do resto dos restos que nem ao menos serve para a alimentação de porcos.

A encíclica "Populorum Progressio" permanece um grito atual, pois "[...] faz um apelo solene a uma ação organizada" (PAULO VI, 1967, n. 4) ao mesmo tempo que entende que 
as iniciativas locais e individuais já não bastam, pois a situação de mundo exige uma ação em conjunto, esclarecendo, de antemão, que a Igreja não quer nem pode imiscuir-se na política dos Estados, reconhecendo a soberania dos poderes eclesiástico e civil e propondo a sua missão: "[...] vivendo na história, deve 'estar atenta aos sinais dos tempos e interpretá-los à luz do Evangelho'. Comungando nas melhores aspirações dos homens e sofrendo de os ver insatisfeitos, deseja ajudá-los a alcançar o pleno desenvolvimento" (PAULO VI, 1967, n. 13).

Ao falar de desenvolvimento, no tocante inicial proposto pelo Monsenhor Bruno-Marie Duffé em sua conferência sobre a consideração da dignidade humana, faz-se necessário olhar para a pessoa humana enquanto tal, pois cada um é único, e o desenvolvimento deverá estar atrelado à cada pessoa, e não somente à economia de mercado, como sugere a encíclica: "O desenvolvimento não se reduz a um simples crescimento econômico. Para ser autêntico, deve ser integral, quer dizer, promover todos os homens e o homem todo" (PAULO VI, 1967, n. 14).

Desse modo, cada ser humano "[...] permanece o artífice principal do seu êxito ou fracasso", mesmo que influenciados direta ou indiretamente por forças externas que o ajudem ou atrapalhem durante a vida, recebem de Deus as prerrogativas de aptidões e qualidades necessárias para desenvolver-se, para fazê-las render, permitindo "[...] a cada um orientar-se para o destino que the propõe o Criador" (PAULO VI, 1967, n. 15).

Em detrimento disso, no contexto de mundo da encíclica, do filme e de hoje em dia, ainda vigora a teleologia das posses; ou seja, quem possui mais quer cada vez mais, sendo esse o fim último da existência mundana. Contra esse dado, a encíclica chama a atenção para o desenvolvimento do crescimento ambivalente, não deixando que a avareza seja empecilho nem obstáculo para o desenvolvimento moral e social: "A busca exclusiva do ter, forma então um obstáculo ao crescimento do ser e opõe-se à sua verdadeira grandeza: tanto para as nações como para as pessoas, a avareza é a forma mais evidente do subdesenvolvimento moral" (PAULO VI, 1967, n. 19).

Torna-se interessante, neste ponto, elucidar junto com o Pontífice o "[...] verdadeiro desenvolvimento, que é para todos e cada um, a passagem de condições menos humanas a condições mais humanas" (PAULO VI, 1967, n. 20). Não há verdadeiro desenvolvimento sem antes assumir valores que transcendam a imanência humana; que coloquem cada pessoa e todas as pessoas de olhos abertos às necessidades mais ínfimas que brotam dos corações angustiados e que as leve a se colocar a serviço umas das outras, transgredindo a norma excludente a partir dos interesses capitalistas.

Nesse ínterim, Monsenhor Bruno-Marie Duffé chamava atenção em sua conferência para o dom da gratuidade da criação de Deus, pois se de graça se recebe, de graça se deve dar, insistia ele, de acordo com o que a referida encíclica trata acerca do destino universal dos bens:

'Enchei a terra e dominai-a': logo desde a primeira página, a Bíblia ensina-nos que toda a criação é para o homem, com a condição de ele aplicar o seu esforço inteligente em valorizá-la e, pelo seu trabalho, por assim dizer, completá-la em seu serviço. Se a terra é feita para fornecer a cada um os meios de subsistência e os instrumentos do progresso, todo homem tem direito, portanto, de nela encontrar o que lhe é necessário (PAULO VI, 1967, n. 22). 
Quando este ponto é iniciado afirmando a importância da páscoa na condução da vida da Igreja, é justamente para enfatizar que a força que a Ressurreição de Cristo trouxe à humanidade foi capaz de dissipar a mácula do pecado, além de ter sido um grito ensurdecedor e definitivo sobre a morte.

Isso sugere que ao assinar e divulgar a encíclica em questão, São Paulo VI pôde trazer à tona algo que permaneceu talvez quieto ao longo da história da Igreja, mas que carrega um movimento de ressurreição na boca dos Santos Padres. Mais especificamente, citando Santo Ambrósio de Milão: "[...] 'não dás da tua fortuna, assim afirma Santo Ambrósio, ao seres generoso para com o pobre, tu dás daquilo que lhe pertence. Porque aquilo que te atribuis a ti, foi dado em comum para uso de todos. A terra foi dada a todos e não apenas aos ricos'" (PAULO VI, 1967, n. 23).

A tarefa do cristão é colocar-se a serviço dos mais necessitados, pois se a criação é dom de Deus a todos, há a necessidade urgente de construir uma comunidade humana, atenta às exigências do tempo presente, socorrendo quem precisa porque não possui o mínimo, enquanto poucos continuam a possuir as maiores riquezas econômicas do mundo todo.

É necessário sim, como diz a encíclica, "[...] reconhecer com toda a justiça o contributo insubstituível da organização do trabalho e do progresso industrial na obra do desenvolvimento" (PAULO VI, 1967, n. 26). Contudo, o mesmo parágrafo chama a atenção para o fato de que:

[...] sobre estas novas condições da sociedade, construiu-se um sistema que considerava o lucro como motor essencial do progresso econômico, a concorrência como lei suprema da economia, a propriedade privada dos bens de produção como direito absoluto sem limite nem obrigações sociais correspondentes. [...]. Nunca será demasiado reprovar tais abusos, lembrando, mais uma vez, solenemente, que a economia está a serviço do homem (PAULO VI, 1967, n. 26).

O grito pascal de ressurreição dessa encíclica vai na contramão daquilo que rege a sociedade, firmada no acúmulo de posses e bens materiais e imateriais, móveis e imóveis, em detrimento de tantos outros que nada possuem. São Paulo VI propõe, ainda, que "[...] só a iniciativa individual e o simples jogo da concorrência não bastam para assegurar o êxito do desenvolvimento. Não é lícito aumentar a riqueza dos ricos e o poder dos fortes, confirmando a miséria dos pobres e tornando maior a escravidão dos oprimidos" (PAULO VI, 1967, n. 33).

Desse modo, a reflexão contida nessa primeira parte da carta encíclica culmina na necessidade da promoção de um humanismo total, que ultrapasse o humanismo exclusivo - que é desumano -, mas que se abra ao absoluto, pois " [...] o homem, longe de ser a norma última dos valores, só se pode realizar a si mesmo, ultrapassando-se" (PAULO VI, 1967, n. 42).

O título deste tópico é o mesmo do da conclusão da encíclica, a saber, "Desenvolvimento é o novo nome da paz". A preocupação com a paz está para além da ausência das guerras:

As excessivas disparidades econômicas, sociais e culturais provocam, entre os povos, tensões e discórdias, e põem em perigo a paz. Como dizíamos aos Padres conciliares, no regresso da nossa viagem de paz à ONU, 'a condição das populações em fase 
de desenvolvimento deve ser objeto da nossa consideração, ou melhor, a nossa caridade para com todos os pobres do mundo, e eles são legiões infinitas, deve tornar-se mais atenta, mais ativa e mais generosa'. Combater a miséria e lutar contra a injustiça, é promover não só o bem-estar mas também o progresso humano e espiritual de todos e, portanto, o bem comum da humanidade. A paz não se reduz a uma ausência de guerra, fruto do equilíbrio sempre precário das forças. Constrói-se, dia a dia, na busca de uma ordem querida por Deus, que traz consigo uma justiça mais perfeita entre os homens (PAULO VI, 1967, n. 76).

\section{O Reino de Deus para além da utopia}

Diante do exposto, faz-se necessário refletir sobre o modo cristão de conceber a dignidade humana dentro de uma sociedade que promova um humanismo total, aberto ao absoluto. Essa compreensão cristã tem base na reflexão sobre o Reino de Deus, que foi uma novidade apregoada por Jesus Cristo em seus ensinamentos e ditos.

Segundo Boff (1980, p. 62) "Jesus inicialmente não pregou nem a si mesmo nem a Igreja, mas o Reino de Deus. Reino de Deus é a realização da utopia fundamental do coração humano de total transfiguração deste mundo, livre de tudo o que o aliena, como sejam a dor, o pecado, a divisão, a morte". Ou seja, dentro do coração humano existe algo de transcendente que o conduz à plenitude da vida, maior que qualquer instituição humana, totalmente voltada para Deus.

As utopias não se realizarão completa e favoravelmente, mas colocam o ser humano no caminho da vida, com a esperança de dias e situações melhores. É a esperança que mora nas entranhas da vida humana e que projeta ao ser humano algo de bom depois das situações ruins que a vida lhe apresenta. A dor, o sofrimento, a fome e a miséria podem ser ultrapassados pelas pessoas que mantêm acesas as lamparinas de suas utopias.

Do mesmo modo, as utopias não devem alienar o ser humano no caminho da vida, nem anestesiar a dor e o sofrimento. Jesus, ao dar ao ser humano a vida como dom gratuito de Deus a serviço dos irmãos e irmãs, também não deixou que a esperança de um mundo novo, liberto, recriado, pudesse envaidecer o ser humano e o afastar da sua realidade sofredora: "Ele, portanto, não veio alienar o homem e levá-lo para outro mundo. Veio confirmar uma boa notícia: esse mundo sinistro tem um fim bom, humano e divino" (BOFF, 1980, p. 62).

Sendo assim, há que se considerar indubitavelmente o próprio Jesus como a Palavra encarnada de Deus na história humana. Ele revelou a vocação própria do ser humano, orientado para Deus, como seu fim e meta. Além de tudo, como diz Boff (1980, p. 63), "Jesus Cristo quer ser em sua própria pessoa a resposta de Deus à condição humana". Para que essa resposta seja levada a cabo, trouxe o Reino de Deus como proposta de vida não alienada, mas encarnada na vida, nas questões mais críticas possíveis, para dar um novo alento, um novo significado, inebriado de ressurreição e capaz de fazer novas todas as coisas (Ap 21,5).

Antes de qualquer coisa, o "Reino de Deus - que ocorre 122 vezes nos evangelhos e 90 na boca de Jesus - significava para os ouvintes de Jesus a realização de uma esperança, no final do mundo, de superação de todas as alienações humanas, da destruição de todo o mal" 
(BOFF, 1980, p. 65). Os ouvintes de Jesus tinham dificuldade em compreender a proposta de uma sociedade alternativa, se assim se pode dizer, que é o Reino de Deus, trazido e inaugurado a partir do Mistério Pascal de Cristo. A compreensão a respeito do Reino de Deus, naquela época e, ainda hoje, estaria ligada a uma promessa de realização futura, no fim dos tempos, mas que não tem hora nem dia marcados.

Sim, a plenitude do Reino de Deus pertence ao tempo kairológico; ou seja, pertence a Deus unicamente. Contudo, a proposta de vida nova inaugurada na páscoa de Cristo é que, segundo Boff, o "Reino de Deus é a revolução e a transfiguração total, global e estrutural desta realidade, do homem e do cosmos, purificados de todos os males e repletos da realidade de Deus. Reino de Deus não quer ser um outro mundo, mas o velho mundo transfigurado em novo" (BOFF, 1980 , p. 66). Não seja, pois, a compreensão a respeito do Reino de Deus, ligada a um depois, mas que seja contemplada no agora histórico, pois há uma realidade sombria que desafia a criação de Deus a reinventar-se cotidianamente para poder se adequar às propostas evangélicas do reinado de Deus nesta sociedade.

É verdade que a proposta de Jesus conduz a humanidade e o cosmos à plenitude de Deus, que acontecerá, segundo a fé em suas palavras, no fim dos tempos, e que todos caminhamos para essa meta final. A criação toda e a humanidade aguardam ansiosamente o cumprimento das promessas de Deus, e a realização dessas promessas não estará relegada unicamente ao fim enquanto final dos tempos, mas no hoje da história de cada crente e, por sua fé, dos demais homens e mulheres de boa vontade. Nas palavras de Boff, "Jesus se levanta na Galiléia e proclama: ele trará o ano da graça do Senhor! Ele realizará uma velha utopia do povo! O egoísmo será superado por uma nova ordem das coisas deste mundo" (BOFF, 1980, p. 67).

Quando Jesus se levanta na Galiléia para a proclamação da irrupção do Reinado de Deus na história do ser humano e todo o cosmos, é intrinsecamente necessário afirmar que o ato de levantar-se, em grego (anástasis), tem o mesmo significado que o ato da ressurreição. Ou seja, no momento exato em que o Crucificado-Ressuscitado faz a proclamação do Ano da Graça do Senhor a partir de sua ressurreição, tudo foi reconduzido à dinâmica de Deus no já da história, em busca do "ainda não". Já aconteceu a recapitulação da história em Deus pela ressurreição de Jesus, mas ainda acontecerá em plenitude no fim dos tempos. Esse evento salvífico se expressa no conceito do Reino de Deus, que, "[...] como transparece, implica dinamismo, notifica um acontecimento, e exprime a intervenção de Deus já iniciada, mas ainda não totalmente acabada" (BOFF, 1980, p. 69).

Não se pode tecer uma reflexão abstrata sobre a intervenção de Deus na história. O Reino de Deus "[...] é a totalidade desse mundo material, espiritual e humano agora introduzido na ordem de Deus" (BOFF, 1980, p. 69).

Ao mesmo tempo, sendo Deus, e voltando para Deus, "Cristo tem consciência de que com ele já se iniciou o fim deste velho mundo. Ele mesmo já pertence ao Reino. A participação na nova ordem está condicionada à adesão à pessoa e à mensagem de Jesus" (BOFF, 1980, p. 70). Desse modo, o Reino de Deus aparece como proposta e não como imposição. Se é proposta, está condicionada à aceitação ou não de quem ouve a pregação do evangelho.

Ao encarnar-se, Cristo assumiu sobre si a humanidade pecadora dos seres humanos. A encarnação é uma realidade e não a abstração de uma possibilidade de fé. A fé cristã é encarnada; 
ou seja, ao assumir a condição humana, Deus assumiu para si a totalidade da criação. Nas palavras de Boff (1980, p. 75) "[...] a encarnação de Deus não significa apenas que Deus se fez homem. Quer dizer muito mais. Ele participou realmente de nossa condição humana e assumiu nossos anseios mais profundos". Talvez se possa dizer que o germe do Reino de Deus já estava colocado nos corações humanos para que, ao resgata-los, Deus pudesse encontrar neles a possibilidade criadora e recriadora de um mundo novo. Não dá para pensar que se o ser humano é criatura de Deus e que o próprio Senhor depositou nele sua confiança a respeito do cuidado com a criação toda mesmo sendo ele total e exclusivamente inclinado ao mal, à violência e à exclusão dos outros.

Desse modo, mesmo que seja uma intervenção de Deus na história humana, o Reino de Deus não pode ser compreendido verticalmente, mas está colocado no coração de cada ser humano para que, diante das injustiças sociais, da fome, da miséria e da violência, tenha a capacidade criadora de uma nova situação, de um mundo novo. A utopia que jaz no coração humano não é só utopia desde a ressurreição de Cristo, mas uma realidade: "O Reino de Deus que ele pregou já não é mais uma utopia humana impossível. Mas 'porque a Deus nada é impossível' (LC 1,37), ele é uma realidade já incipiente dentro de nosso mundo" (BOFF, 1980, p. 75).

Além disso, o Reino de Deus, enquanto compreensão de uma possível sociedade alternativa à organização vigente, faz do ser humano um buscador de Deus na pessoa e na pregação de Jesus de Nazaré. Quem se encanta com sua Boa Nova, se sente apaixonado, assim como Ele, pela novidade de Deus, capaz de dar vida nova às realidades existenciais. Mas não basta apaixonar-se, é necessário comprometer-se com essa nova realidade a partir de uma adesão fundamental. Jesus, segundo Boff (1980, p. 77), "[...] é o homem novo, o Reino já presente, embora sob os véus da fraqueza. Aderir a Cristo é condição indispensável para participar na nova ordem a ser introduzida por Deus (LC 12,8-9)".

Essa adesão fundamenta-se numa conversão radical a Cristo e "[...] não consiste em exercícios piedosos. Mas num novo modo de existir diante de Deus e diante da novidade anunciada por Jesus" (BOFF, 1980, p. 77). É deixar pulsar dentro de si as batidas do coração de Deus, que ama, protege, cuida e zela por todos e pela criação total. É apaixonar-se e comprometer-se com a vida em suas facetas mais ameaçadas.

Aquilo que foi dito sobre o desenvolvimento humano integral encontra campo e matéria no que a Igreja compreende como Reino de Deus. Todos foram chamados por Deus à felicidade e essa felicidade se realiza num modo de vida voltado para fora de si, como afirma Boff (1980, p. 81) "[...] o amor deve ligar todos os homens entre si", haja vista que "[...] o amor não conhece limites. Exige fantasia criadora. Só existe no dar e no pôr-se a serviço dos outros. E é só dando que se tem" (BOFF, 1980, p. 83). Em sua conferência, Monsenhor Bruno-Marie Duffé não se cansou de dizer e enfatizar essa verdade: recebe-se de graça e de graça se deve dar. Para que haja o desenvolvimento integral humano, há a necessidade urgente de compreender o amor como a ligação fundamental que transformará as relações humanas de dentro para fora das próprias pessoas.

Essa realidade de desenvolvimento humano e integral só é possível dentro da compreensão cristã de Reino de Deus enquanto uma sociedade alternativa que se fez utopia no coração humano como desejo, e que se torna realidade no campo ético da prática cristã. Quando a utopia se torna ortopraxia, há a iminência do Reino de Deus, e isso pode se tornar visível no desenvolvimento 
humano e integral da pessoa humana, haja vista que "[...] as atitudes de Jesus devem ser seguidas por seus discípulos. Elas inauguram no mundo um novo tipo de homem e de humanismo, que nós cremos ser o mais perfeito que jamais surgiu com capacidade de assimilar valores novos e alheios sem trair sua essência" (BOFF, 1980, p. 91).

O grito dos oprimidos, o gemido dos pobres, a violência e a insatisfação com as realidades pecaminosas deste mundo não podem passar despercebidas pelos seguidores de Jesus, pois, como afirma Boff (1980, p. 91):

Quem como Jesus sonhou com o Reino dos céus não se contenta mais com esse mundo assim como ele se encontra. Ele se sente, frente a esse mundo cheio de ambiguidades, como um 'paroquiano', no sentido primitivo e forte que a palavra tinha para $\mathrm{S}$. Clemente Romano (+97) ou para Santo Irineu (+202), isto é, sente-se estrangeiro a caminho de uma pátria mais humana e feliz. Por algum tempo deve morar aqui mas sabe que desde que apareceu Jesus o homem pode sonhar com um novo céu e uma nova terra.

Enfim, considerar a dignidade da pessoa humana é estar aberto à proposta de um mundo novo, capaz de suprir as necessidades individuais sem cair no individualismo, mas tendo como horizonte o Reino de Deus, inaugurado na páscoa de Cristo, enquanto realidade iminente. Desse modo, urge a necessidade de despertar a utopia que reside no coração humano para que o mesmo ser humano, cada um e todos, compreenda-se como participantes de uma comunidade única no mundo, sendo artífice do próprio desenvolvimento e não se ausentando, mas se comprometendo em salvar os irmãos e irmãs mais necessitados.

\section{Considerações Finais}

Ao final deste artigo, faz-se necessário retomar os pontos fundamentais que tiveram como objetivo alargar o horizonte de reflexão a partir da conferência "O que quer dizer considerar a dignidade da pessoa humana?", proferida pelo Monsenhor Bruno-Marie Duffé, Secretário do Dicastério para o Desenvolvimento Humano Integral - Vaticano, considerando-a a partir da análise da primeira parte da encíclica "Populorum Progressio - sobre o desenvolvimento dos povos", do Papa São Paulo VI.

Ao compreender a tarefa da Igreja em se fazer a porta-voz de tantas pessoas que são oprimidas pela fome, exclusão, violência, entre outras situações de calamidade pública, fez-se necessário entender que a pessoa humana é artífice de seu próprio desenvolvimento e, para que haja desenvolvimento humano e que esse seja integral, há a necessidade de promover todos os homens e o homem todo, não se apoiando apenas no campo econômico.

Desse modo, a compreensão cristã a respeito de uma sociedade alternativa em que haja e aconteça o pleno desenvolvimento humano e integral se dá a partir do entendimento acerca do Reino de Deus enquanto utopia presente no coração humano e que encontrou sua expressão na páscoa de Cristo, que inaugurou o Reinado de Deus como proposta de realidade iminente. Para que isso aconteça de fato, há a necessidade de conversão da pessoa e a adesão à proposta e à pessoa de Jesus Cristo, sabendo que o seguidor de Jesus é movido pelo amor que brota do seu divino coração e que o deixa inquieto diante das injustiças sociais. 


\section{Referências}

BOFF, L. Jesus Cristo Libertador: ensaio de Cristologia Crítica para o nosso tempo. Petrópolis: Vozes, 1980.

DUFFÉ, B.-M. O que quer dizer considerar a dignidade da pessoa humana? Campinas: PUC-Campinas, 2019. Publicado pelo canal da PUC-Campinas. Disponível em: https://www.youtube.com/watch?v=VZqwKVbCJqk\&list=PLIplquhLI8eNR qrsv7hZbqxeV0y8M97AY\&index=10. Acesso em: 22 set. 2021

ILHA das Flores. Escrito e dirigido pelo cineasta Jorge Furtado. Porto Alegre: Casa de Cinema de Porto Alegre, 1989. Disponível em: https://www.youtube.com/watch?v=FIRLNeNzMAk. Acesso em: 28 ago. 2021.

PAULO VI, Papa. Carta Encíclica Populorum progressio (sobre o desenvolvimento dos povos). São Paulo: Paulinas, 1967.

Como citar este artigo/How to cite this article

NEGRO, F. M. Dignidade da pessoa humana: ortopraxia cristã ou utopia? Cadernos de Fé e Cultura, v. 6, e215489, 2021.

https://doi.org/10.24220/2525-9180v6e2021a5489 